\title{
COMPLEX SUICIDE-A NOVEL CASE REPORT AND A BREIF REVIEW OF LITERATURE
}

\author{
Dina Galal Ibrahim \\ Forensic Medicine and Clinical Toxicology Department, Cairo University, Egypt. \\ Corresponding author: Dina Galal Ibrahim \\ e-mail: dina.galal@kasralainy.edu.eg \\ Date of submission: 25 May 2020 \\ Revised at: 13 June 2020 \\ Accepted at: 20 June 2020
}

\begin{abstract}
:
Background: Suicides are usually known to be either simple or complex, the latter which is defined as a combination of more than one method. Additionally, complex suicide can be practiced in an unplanned manner where several methods are used, consecutively, when the first method has not achieved the desired outcome. The procedure usually gets changed after the first method chosen failed, was working slowly, or proven to be overly painful. The rotation between failed suicidal acts causes difficulties in determining the manner and the mode of death. Method: In the present study, we will discuss some of the relevant previous studies regarding complex suicide and a systematic approach to managing such cases from a medicolegal perspective. Besides, an unusual case of complex suicide, which was handled in 2018 in the Kuwaiti Forensic Medicine Department, will be presented. She is a middle-aged female, domestic worker, who was found dead in the bathroom, with secured inlets and outlets from inside. She was incompletely hanged with multiple neck, chest, and abdominal cut wounds, apart from bilateral wrist cut. Furthermore, bloody knife, razor and razorblade were found inside the basin. Result and conclusion: After a complete autopsy, forensic pathology and toxicology examination were done, the forensic and crime scene reports together with the criminal investigations were declared. Consequently, the case was reported as a complex suicide case and the cause of death was haemorrhagic shock after lung stabbing. The case represents a novel complex suicide with self-stabbing, wrist cutting and hanging.
\end{abstract}

Keywords: Complex suicide, hanging, stabbing, cut wrist.

\section{INTRODUCTION}

In 1974, Marcinkowski et al. (Sunil et al., 2015) had suggested a general division of suicide pattern which was divided into simple versus complex. The complex is defined as a combination of methods to achieve death. However, when multiple suicidal methods were previously prepared, suicide will be categorized as plannedcomplex. On the other hand, the failure of the prepared mechanism will lead the victim to start with an alternative method of inflicting death, which is categorized as unplanned-complex (Palmiere et al., 2007 and Cascini et al., 2012). Complex suicide is highly distinct from complicated suicide as the latter is characterized by unintentional secondary trauma after the intended suicide method (Töro and Pollak 2009).

Suicide is one of the three main causes of death among the middle aged of all developed/developing countries, while the suicide attempts are 20 times more frequent. Mental disorders (particularly depression) are associated with more than $90 \%$ of all cases of suicide; however, it is more likely to take place during socioeconomic, family, and personal crisis conditions (Al Madani et al., 2011). Stabs have been common throughout human history and one of the most frequent ways of committing homicide and suicide, being cheap and easy to acquire (Ventura et al.,2010).

Proper history, meticulous crime scene investigation and carefully performed 
autopsy are vital in ascertaining the manner of death in such cases (Turk et al., 2004). This article will describe an unplanned complex suicide case that presented with hanging, multiple fatal stab injuries and cut both wrists while labelled as suicide only after a meticulous postmortem examination.

\section{CASE PRESENTATION}

A 41-year-old female Asian house worker was found dead in the bathroom which was securely locked from inside. She was found incompletely hanged with a frontal fixed knot by a bloody piece of cloth. Blood was seen scattered in the death scene mostly below the deceased, and a bloody knife, razor, and a razor blade were all seen in the basin of the bathroom (fig.1). The investigation of the death scene did not find any disorder in the bathroom or trace to another person(s). Blood traces and fingerprints that were referred to the deceased were both found on the knife and the razor blade. The testimony of witnesses of the other house worker and the employer's family revealed that she has been depressed for unknown reasons since she started to work in their house months ago.
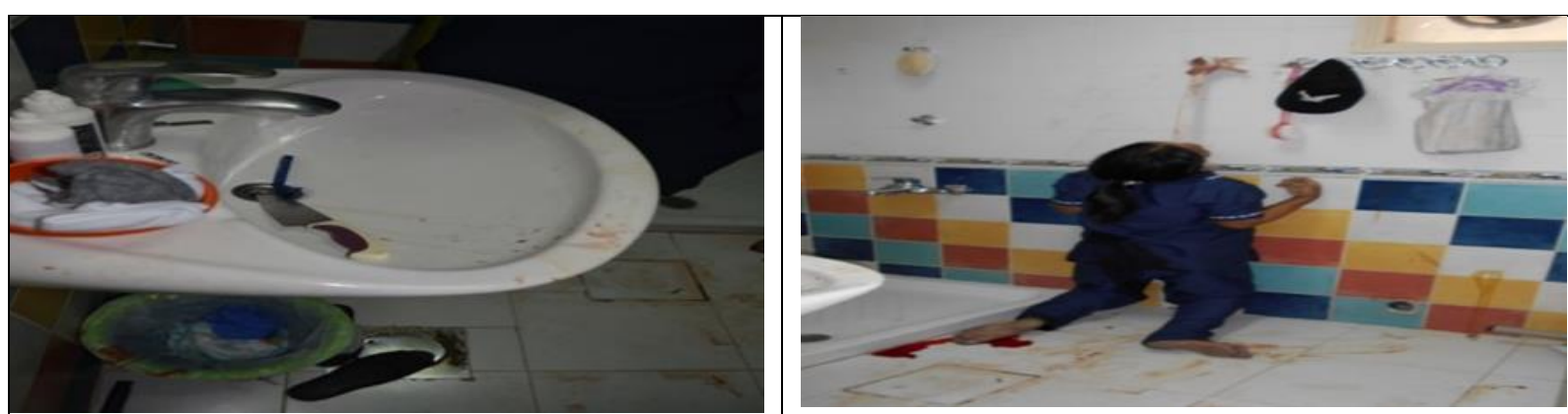

(a)

(b)

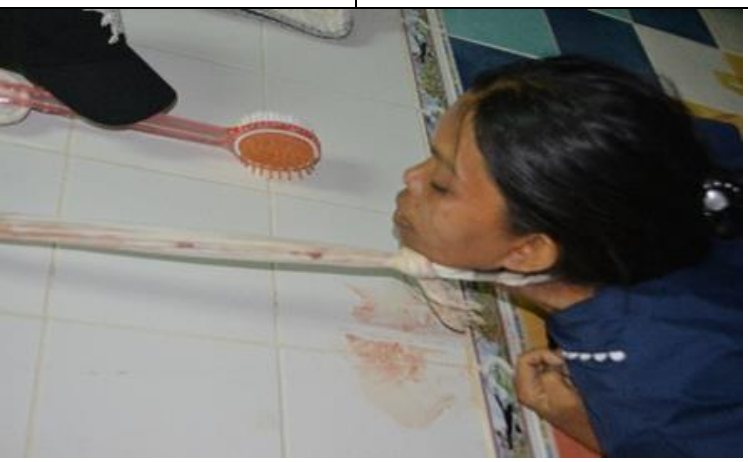

(c)

Figure (1): Crime scene, knife, razor, and razorblade on the bloody basin(a), incomplete hanging with a bloody ligatured cloth with frontal knot $(\mathrm{b}, \mathrm{c})$.

External examination of the body revealed bloody intact uniform and underclothes, free of any cuts or suspicious signs. One end of the ligature, which was a piece of cloth, was bloody mostly near the point of fixation (around a tap up on the wall); its other end was tied around the neck with a frontal fixed knot. (fig. 1b,c). 


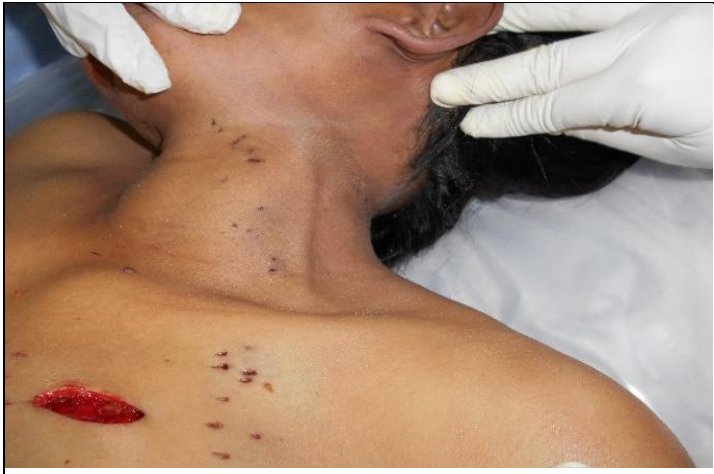

(a)

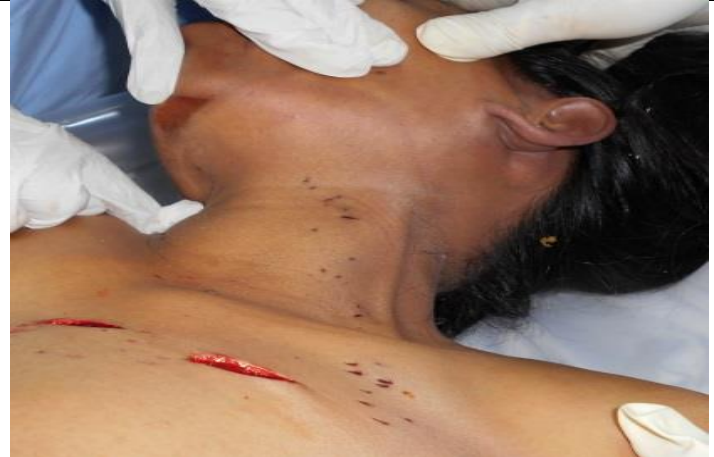

(b)

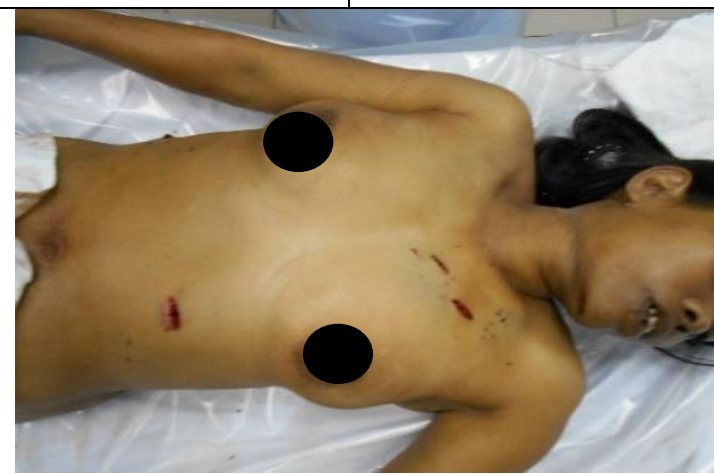

(c)

Figure (2): Faint parchment-like mark under the chin (mark of the knot) with a faint skin linear mark (of the ligature) on the upper sides of the neck(a,b). Hesitation marks seen on the left side of the neck and left upper part of the chest $(a, b, c)$.

Following ligature removal, a faint skin mark just below the hair root on the back of the neck that runs upwards on the sides reaching below the chin was revealed. The hanging mark was directed obliquely upwards towards the suspension point (fig. 2a). Besides, a rounded brown parchment-like mark was found under the chin midline displaying the knot mark (fig. $2 b)$. There was neither congestion in her face nor petechial haemorrhages in skin and eyes. Multiple small superficial wounds were found on the left side of the neck ranging from $1 \mathrm{~mm}$ till $0.5 \mathrm{~cm}$ length with $1 \mathrm{~mm}$ width. On the left side of the upper part of the chest, two oblique deep cut wounds with 2 and $2.5 \mathrm{~cm}$ lengths surrounded by multiple small wounds $1-2$ mm length were found (fig. 2 a,b,c).
On the abdomen, a deep transverse cut wound of $2 \mathrm{~cm}$ length was found on the left side with 3 superficial cut wounds $2 \mathrm{~mm}$ length each just below it. On the right side, there was tow crisscross deep cut wounds of $2 \mathrm{~cm}$ length each, surrounded by multiple superficial cut wounds of 1-2 mm length (fig. 3 a,b). On the flexor surface of both wrist joints, a superficial transverse cut wound of $1.5 \mathrm{~cm}$ and $2 \mathrm{~cm}$ length of the right and left sides consecutively were found. Besides, dry blood traces were found in both hands (fig.3 c,d). The hypostasis was very faint at the back of the body and pregnancy test along with the toxicology screening test in urine were both negative. 


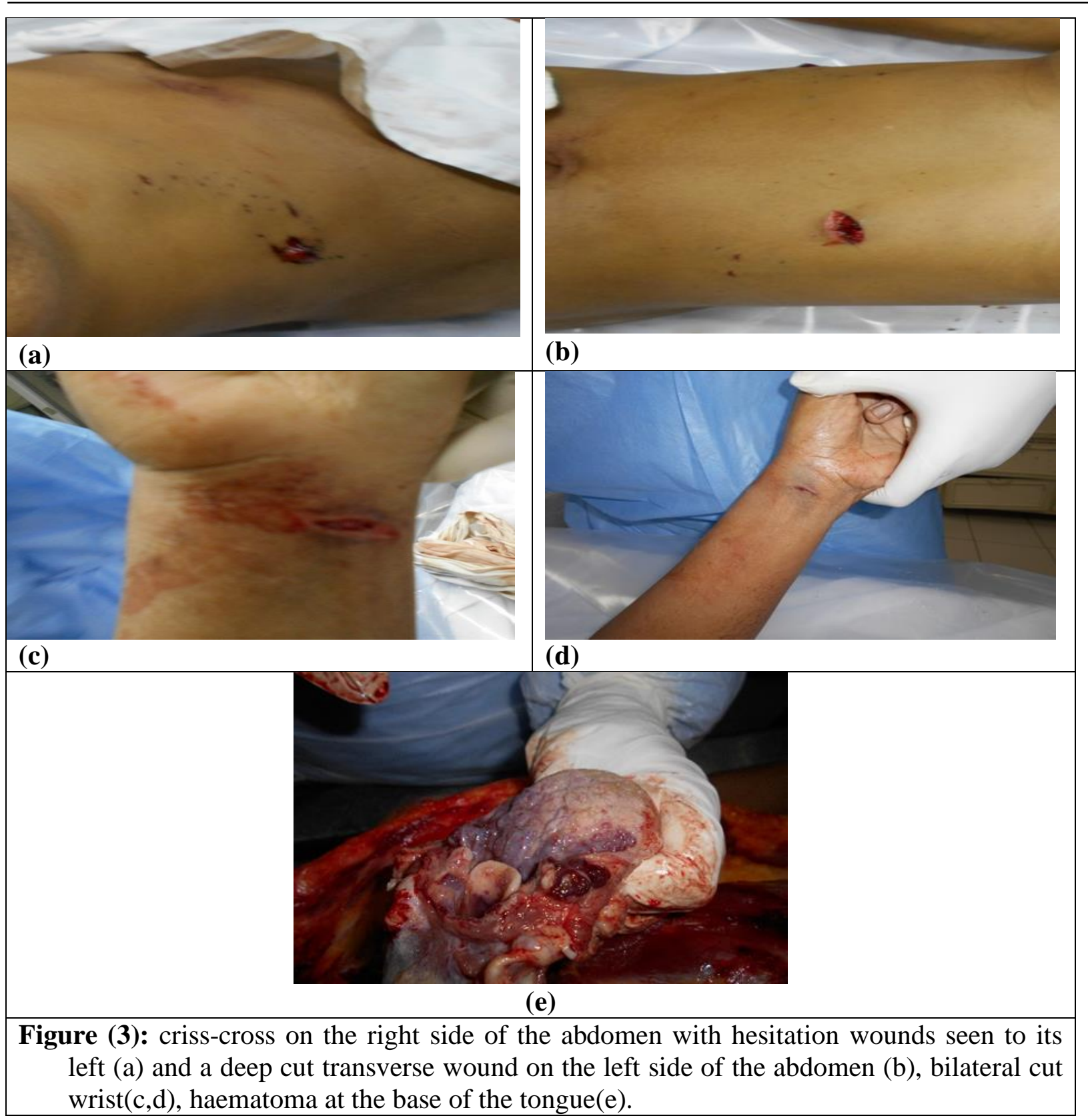

On autopsy, neck structures were free of any pale or haemorrhagic areas except for a limited haematoma on the base of the tongue (fig. 3e). The cervical spines, hyoid bone and laryngeal cartilages were intact. On the left side of the chest, a penetrating wound in the second left intercostal space was found to be passing to the upper lobe of the left lung causing a cut wound of 1 cm length on it and another cut wound in the chest was found as none penetrating. However, the left lung was found to be collapsed. Both lungs were very pale (fig. 4 a,b). Inside the chest cavity and after removal of lungs, about $200 \mathrm{ml}$ of liquid blood was found in the back of the left side. In terms of the abdomen, two penetrating wounds were found in the right side of the abdomen causing deep cuts in the liver accompanied by nearly half a litre of free haemorrhagic blood that was found in the abdominal cavity (fig. $4 \mathrm{c}, \mathrm{d}$ ).

On histopathology examination, unremarkable changes in the neck soft tissue, except for some congestion in the base of the tongue, were observed. The lung tissue displayed hypovolemic shock changes along with diffuse alveolar injury. However, no signs of asphyxia were observed in the lung tissue. Toxicology 
workup was negative and neither ethyl nor methyl alcohol was found in the blood samples taken from the deceased. Vaginal and anal swabs were negative for semen.
The cause of the death was declared due to hypovolemic shock and lung injury because of severe external haemorrhage after multiple stab injuries.

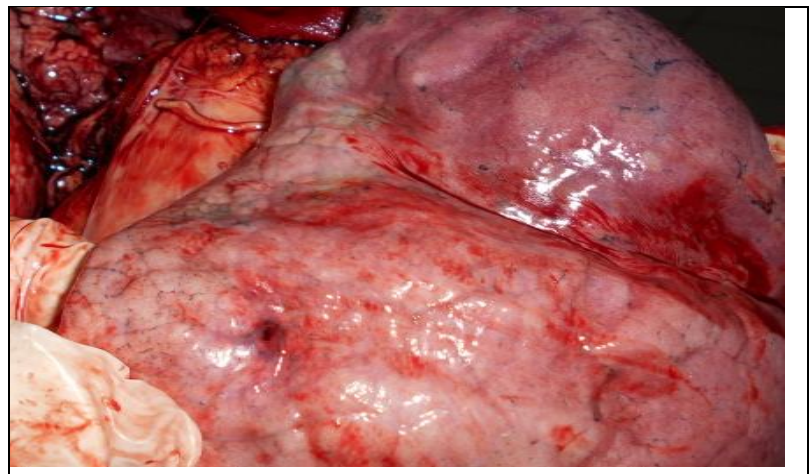

(a)

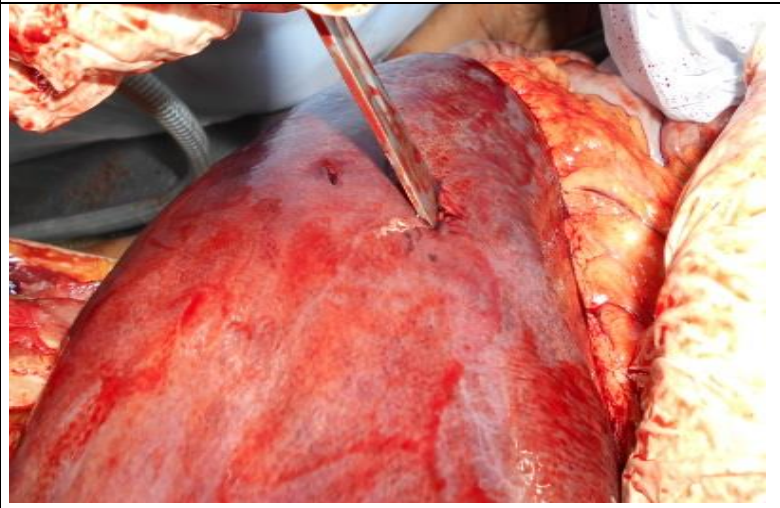

(c)

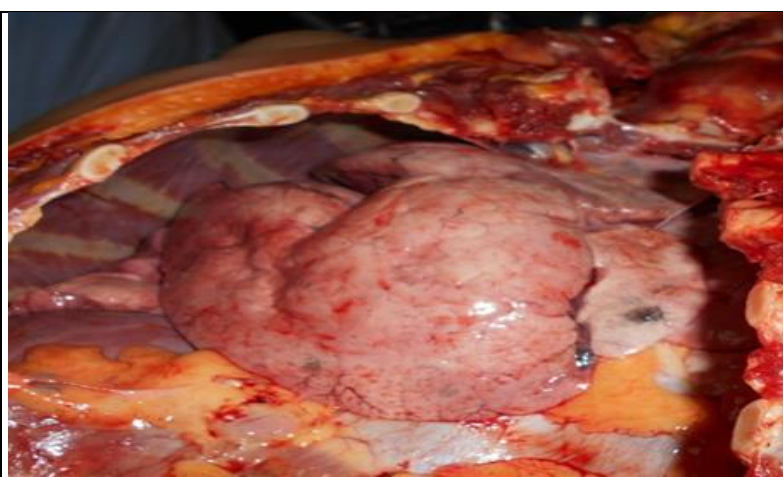

(b)

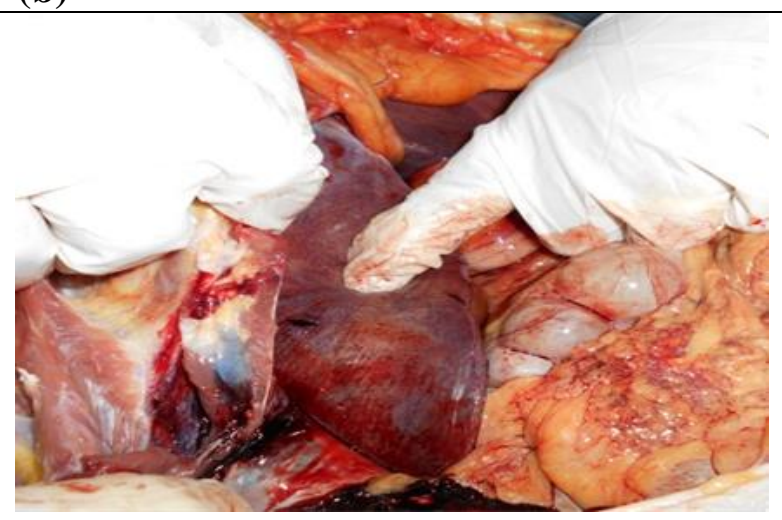

(d)

Figure (4): autopsy showing collapse and injury of the left lung (a,b) and liver injuries (c,d)

Crime scene examination along with the forensic pathology report has suggested a hypothetical scenario. The victim initially started to cut her wrists using the razor blade or the knife after which she commenced on stabbing her-self using the knife. However, no immediate result has occurred, and she was in intense pain. While she was severely bleeding, she started to prepare the ligature cloth for hanging to assure a rapid death. Due to the haemorrhagic shock, a faint hanging mark with minimal viability changes was observed on the neck along with little haemorrhage in the tongue base. Besides, neither pallor nor haemorrhage was found in the neck structure.

\section{DISCUSSION}

In a suicide crime scene, it is not common to see multiple self-destruction methods in a single incident (Gurcan, 2006). The deceased intentionally uses multiple, simultaneously, or chronologically, manners to guarantee a successful suicide (Palmiere et al., 2007). Complex suicides can be challenging for the forensic medical examiner because of the plurality of methods used and here comes the importance of systematically exhaustive post-mortem investigation to ascertain the cause and manner of death in those cases (Ohshima and Kondo, 1997). In the forensic literature, complex suicides have been reported to account for about $1.5 \%$ to $5 \%$ of all suicides (Karger et al., 2000). Cut wounds are commonly the first choice in unplanned complex suicide; however, the resulting prolonged death compels the victim to kill himself by a more rapidly effective method as stabbing or hanging (Byard et al., 2002). Self- 
stabbing being involved in many complex suicide cases studied in forensic could be related to the availability of such weapons and/or the rapid death comes after major organ injury or severe external bleeding (Brunel et al., 2010 and Ohshima and Kondo, 1997).

Crime scene investigation is of major importance to differentiate suicide from homicide deaths. The weapon, which is almost always found at the suicidal scene, is consistent with wound morphology and could help to exclude homicide. The place where the body was discovered is crucial. Criminal studies showed that the most frequently used sight of deaths is the victim's house or place of work as in the current case (Dogan et al., 2014).

The external examination of the body helps to identify many features. The appearance and status of the clothing (covering or raised) help to differentiate between homicide and suicide. In most suicides, the clothing that covers the injured site was absent or intentionally raised (Ohshima and Kondo, 1997 and Karger et al., 2000). In the presented case, clothes were intact which denotes that the deceased had removed the clothes during the stabbing trials. The morphology, location, pattern, and number of wounds are also critical. the pattern of hesitation marks, that are superficial sharp weapon injuries limited to the epidermal or upperdermal layers, are believed to be of the most useful significance in the distinction of suicide from homicide.

Hesitation marks are observed in 62$88 \%$ of suicidal cases (Karlsson, 1998). In the presented case, there were multiple hesitation marks involving the neck, chest and abdomen which are their most common location according to literature. However, sharp weapon injuries must be in an anatomical location accessible to the victim to perform self-harm. For instance, homicide is commonly suggested if wounds were located on the back and genitals (Viel et al., 2009). The popular sites for self-inflicted cut wounds are usually the neck, wrist, and abdomen. In the presented case, wounds were over the left aspect of the neck, left upper chest, right and left wrist joints and right and left sides of the abdomen. Those are all sites for self-infliction and the deceased is most probably a right-handed individual. The total number of the wounds was $>50$ which is uncommon in most cases. Despite that multiple stabs raise homicidal suspicion, many of those injuries could also be found in a few suicidal cases. In (2001), Karger and Vennemann reported a case of suicide with 92 stab wounds. Other recent studies described multiple stabs in different locations such as the neck, chest, and abdomen. However, in every case of fatal sharp-weapon injuries, a set of arguments is crucial to differentiate between homicide and suicide (Karlsson, 1998).

Hanging is one of the 10 leading causes of death worldwide accounting for more than a million deaths annually. According to literature, as represented in this case, medico-legal diagnosis of suicide is only possible by observation of data collected from the autopsy, toxicological analysis, and circumstances along with death scene studies. Many others declared many cases of complex suicide, the hanging being mostly the last method used and the final leading cause of death. In 2000, Mariano and Dimitra stated two cases of complex suicide where hanging was the leading cause of death after dissection and histopathological examination. The first was a gunshot in the head before hanging and the other was a case where the deceased hanged himself before the fire ignited the shrubs below the hanged body that started to burn (Mariano and Dimitra, 2000).

The literature revealed multiple factors to favour the suicide hypothesis in stabbing cases. This includes the absence of disturbance in the death scene, blood limited to the body location, naked injured area and transverse/oblique situated cut wounds associated with suitable wrist 
positioning during self-stabbing. Besides, the rareness of rib injuries in case of chest self-injuries, extreme variability of stab wounds depth, hesitation marks (tentative cuts) near the target wound, and dried blood on the hands of the victim without any defensive injuries (Palmiere et al., 2007).

\section{CONCLUSION}

The demonstrated incident can be an unprecedented model of a suicide event through multiple self-cutting, stabbing followed by hanging. Management of the complex suicide cases, while multiple various types of injuries are present, can be doubtful as indicating homicide. Investigating the circumstances along with a precise screening of the scene of death, a comprehensive autopsy and a methodical toxicology analysis are necessary to elucidate the correct mode of death in such cases. However, the autopsy revealed, in this case, that stab wounds were the leading cause of death and not hanging. A hypothesis was done that the victim planned suicide by self-cutting along with stabbing. Consequently, hanging was done, which was a spare method, to terminate a slow, painful death. In this reconstruction, the case can be defined as a bizarre type of planned complex suicide.

\section{REFRENCES}

Al Madani, O.M. ; Kharoshah, M.A. ; Youssef, M.A. and Moulana, A.A. (2011): Multiple suicidal firearm injuries: A case study. Egyptian Journal of Forensic Sci., 1: 140-143.

Brunel, C.; Fermanian, C.; Durigon, M. and De la Grandmaison, G.L. (2010) : Homicidal and suicidal sharp force fatalities: autopsy parameters in relation to the manner of death. Forensic Sci Int., 198: 150-154.

Byard, R.W.; Klitte, A.; Gilbert, J.D. and James, R.A. (2002): Clinicopathologic features of fatal self-inflicted incised and stab wounds: a 20-year study. Am J Forensic Med Patho., 1(23): 15-8.

Cascini, F.; Longo, F.; Polacco, M. and Scafetta, I. (2012): Foreign object ingestion in complex suicide: A case report and review of the literature. Forensic Sci. int., 219: 1-3.

Dogan, K.H.; Demirci, S. and Deniz, I. (2014): An unusual complex suicide by corrosive ingestion and stabbing. Case Reports. Clin. Pathology, 1: 813.

Gurcan, A. (2006): Planned complex suicide: Report of three cases. Forensic Sci. Int., 157 : 83-86.

Karger, B.; Niemeyer, J. and Brinkmann, B. (2000): Suicides by sharp force: typical and atypical features. Int J Legal Med., 113: 259262.

Karlsson, T. (1998): Homicidal and suicidal sharp force fatalities in Stockholm, Sweden: orientation of entrance wounds in stabs gives information in the classification. Forensic Sc Int., 93: 21-32.

Mariano, C. and Dimitra, T. (2000): Planned complex suicide. Report of three cases. The American $\mathrm{J}$ of forensic medicine and pathology.21(3):255-260.

Ohshima, T. and Kondo, T. (1997): Eight cases of suicide by self-cutting or stabbing consideration from medicolegal viewpoints of differentiation between suicide and homicide. J Clin Forensic Med., 4: 127-32.

Palmiere, C.; Risso, E.; Van Hecke, O. and La Harpe, R. (2007): Unplanned complex suicide by self-strangulation associated with multiple sharp force injuries: a case report. Med Sci Law, 47: 269-273.

Sunil, G.V.; Harish, P.; Manoj, P.; Rajesh, S. and Vikas, M. (2015) : A planned complex suicide: Cut injury to the wrist with corrosive acid poisoning. Egyptian Journal of Forensic Sciences,6(4):478-480 
Töro, K. and Pollak, S. (2009): Complex suicide versus complicated suicide. Forensic Sci Int., 184(1-3): 6-9.

Turk, E.E.; Anders, S. and Tsokos, M. (2004): Planned complex suicide Report of two autopsy cases of suicidal shot injury and subsequent self-immolation. Forensic Sci Int., 139: 35-38.
Ventura, F.; Bonsignore, A.; Gallo, M.; Portunato, F. and De Stefano, F. (2010): A fatal case of suicidal stabbing and cutting. Journal of Forensic Leg Med., 17: 120-122.

Viel, G.; Cechetto, G. and Montisci, M. (2009): An unusual case of suicide by sharp force. Forensic Sci Int., 184: 1215. 


\section{الملخص العربي \\ الاتتحار المركب: دراسة حالة جديده ومراجعة المؤلفات \\ دينا جلال ابراهيم \\ قسم الطب الثر عي و السموم الإكلينيكية، كلية الطب، جامعة القاهرة}

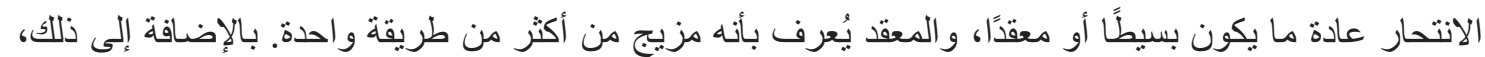

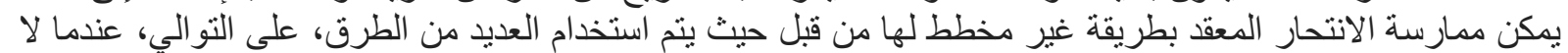

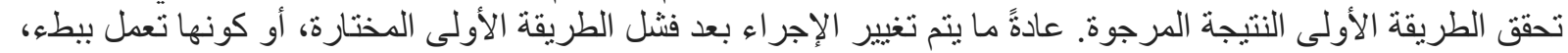

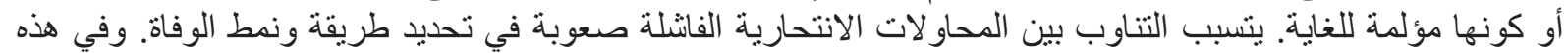

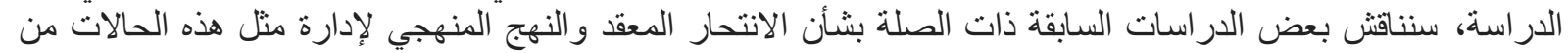

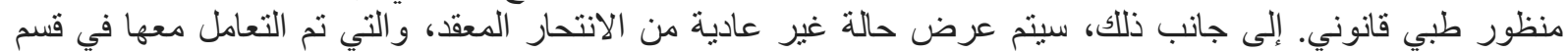

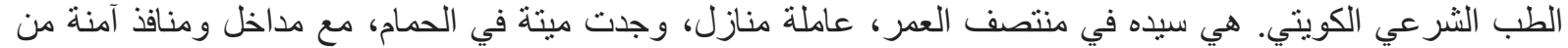

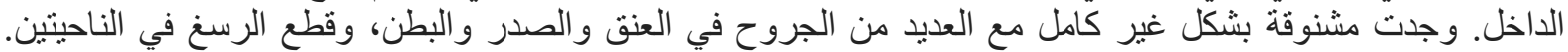

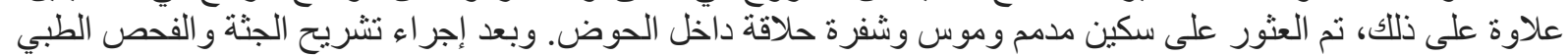

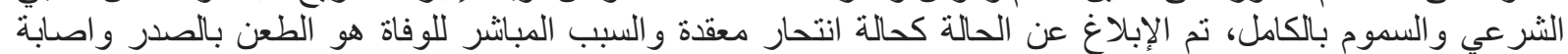

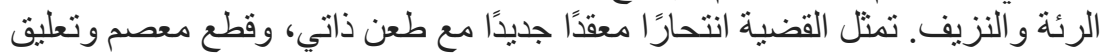

